\title{
Seed Transmission of Cephalosporium gramineum in Winter Wheat
}

\author{
Timothy D. Murray, Professor, Department of Plant Pathology, Washington State University, Pullman 99164-6430
}

\begin{abstract}
Murray, T. D. 2006. Seed transmission of Cephalosporium gramineum in winter wheat. Plant Dis. 90:803-806.

Although isolation of Cephalosporium gramineum from wheat (Triticum aestivum) seed has been reported, development of Cephalosporium stripe in plants from infected seed has not been demonstrated experimentally. Winter wheat seed was collected from three experimental field plots where Cephalosporium stripe was present, and C. gramineum was isolated from the seed following surface-disinfection and incubation on a semi-selective medium. C. gramineum was isolated from 0.10 to $0.88 \%$ of seed from 11 of 12 cultivars in a field experiment at Pullman, WA, and from 0.10 to $0.30 \%$ of seed from 3 of 4 genotypes in a field experiment at Fort Hall, ID; differences among cultivars were not significant in either experiment. C. gramineum was isolated from 0.35 and $0.55 \%$ of cv. Stephens plants with no symptoms and severe symptoms, respectively, from a uniform seeding in Pullman. Seed of the four genotypes from Fort Hall and Stephens from Pullman were grown under controlled environment in a soilless potting mix with no added inoculum and in which C. gramineum was not detected. Symptoms of Cephalosporium stripe developed in 0.08 and $0.17 \%$ of Stephens and breeding line $87-00314 \mathrm{~A}$ plants, respectively, from Fort Hall, and from 0.18 and $0.55 \%$ of Stephens plants with no symptoms and severe symptoms, respectively. Although development of Cephalosporium stripe in plants grown from seed lots harvested from diseased plants was low, infected seed can provide an important source of inoculum for introducing the pathogen and initiating epidemics in areas where the pathogen did not occur previously.
\end{abstract}

Additional keywords: vascular wilt disease

Cephalosporium stripe is a vascular disease of winter wheat (Triticum aestivum) caused by the soilborne fungus Cephalosporium gramineum Nisikado \& Ikata (=Hymenula cerealis Ellis \& Everh.). It is a chronic yield-reducing disease that occurs every year in the Pacific Northwest region (Idaho, Oregon, and Washington) of the United States. C. gramineum overwinters as a saprophyte in host residue on or near the soil surface and produces large numbers of single-celled conidia in the autumn when conditions become cool and wet (13). As the primary inoculum, conidia typically infect roots through wounds caused by soil freezing and insect feeding $(8,12)$, although infection can also occur in the absence of root wounding $(2,8,20)$. This fungus colonizes the plant through the xylem, resulting in yellow stripes and brown streaks in leaf sheaths and blades, and may cause premature death $(5,17,21)$. Yield of infected plants may be only $20 \%$ of that of healthy plants when disease is severe, as indicated by symptoms in the flag leaf or head, and thus poses a serious economic problem for growers $(8,9,11)$.

Corresponding author: T. D. Murray

E-mail: tim_murray@wsu.edu

Accepted for publication 2 February 2006.

DOI: 10.1094/PD-90-0803

(C) 2006 The American Phytopathological Society
The primary source of inoculum for Cephalosporium stripe is infested residue from previous crops, although seed could be an important source of inoculum in some situations. Field burning and crop rotation reduce the amount of inoculum present; however, burning is not a widespread practice due to environmental concerns (4). Neither burning nor crop rotation are completely effective in controlling Cephalosporium stripe since the inoculum level required to cause disease is very low (6). Bruehl et al. (6) reported that as little as $30 \mathrm{~kg} / \mathrm{ha}$ of infested debris (added after seeding) under favorable conditions caused 96\% infected stems in 'Stephens', a highly susceptible cultivar, in a field where winter wheat had not been grown for 2 years. Consequently, transmission of $C$. gramineum through seed could represent a significant source of inoculum, especially in fields where the pathogen does not occur or where other control measures such as crop rotation are being used.

Seed has been implicated as a potential source of inoculum of $C$. gramineum. In 1934, Nisikado et al. (17) reported, based on results of field studies, that seed was a minor source of $C$. gramineum inoculum in wheat and barley in Japan. Bruehl (5), in his initial study of Cephalosporium stripe in Washington State in 1955, could not isolate $C$. gramineum from seed of the winter wheat 'Elmar', which was naturally infected, but was able to isolate the pathogen from all aboveground parts of green- house-grown inoculated plants. After observing Cephalosporium stripe occurring in fields where the disease had not previously occurred, Bruehl repeated the experiments and recovered $C$. gramineum from 5 out of 587 seeds harvested from plants that were hypodermically inoculated in the lower stem (5). Bruehl (5) concluded that the pathogen was seed transmitted, but that the rate was too low to produce an epidemic. Arneson and Stiers (1) also concluded that $C$. gramineum was a seedborne pathogen after finding seed infestation ranging from 0.3 to $7.3 \%$ in 11 winter wheat cultivars and breeder lines. Although Arneson and Stiers (1) conducted pathogenicity tests on wheat of the isolates obtained from seed and found the isolates were pathogenic, they did not report transmission to plants originating from infected seed. In 1995, plants grown in a greenhouse from seed harvested from field plots where Cephalosporium stripe was present, but which were not exposed to $C$. gramineum, developed symptoms of Cephalosporium stripe. C. gramineum was subsequently isolated from these plants, thus suggesting the potential for seed transmission (T. D. Murray, unpublished).

The objectives of the current study were to evaluate newer winter wheat cultivars for the presence of $C$. gramineum in seed and to determine if the pathogen is transmitted to plants from infected seed. This work was conducted to determine the potential for seed transmission in current cultivars compared with older cultivars, since the last research on this topic was conducted more than 20 years ago. Additionally, although previous researchers concluded that transmission of the pathogen from seed to plant occurred, none conclusively demonstrated that it occurred in the absence of soilborne inoculum. Preliminary results of this study have been reported (3).

\section{MATERIALS AND METHODS}

Cultural practices. Field plots were located at the Washington State University Plant Pathology Farm (PIP) and the Palouse Conservation Field Station (PCFS) near Pullman, WA, and in a commercial field near Fort Hall, ID (FH). The Pullman plots were planted to winter wheat every other year with an alternate year of fallow on Thatuna silt loam (fine-silty, mixed, mesic xeric Argialboll). At the PIP site, 12 winter wheat cultivars (Table 1) were seeded on 18 September 1995 in four-row plots $(4.5 \times 1.2 \mathrm{~m}$ with $0.3 \mathrm{~m}$ between rows) with a grain drill at approximately 
$90 \mathrm{~kg} / \mathrm{ha}$. However, the same number of seeds was planted in each plot in order to account for differences in seed weight among cultivars. Six replicates were planted for each cultivar in a randomized complete block design. Other cultural practices such as soil fertility and weed control were conducted as described previously $(16,20)$. Oat kernels colonized by $C$. gramineum were used as inoculum and scattered $(200 \mathrm{~kg} / \mathrm{ha})$ on the plot in October $1995(6,7)$.

The PCFS site was seeded uniformly to the cultivar Stephens on 20 September 1995 at a rate of $90 \mathrm{~kg} / \mathrm{ha}$ using certified seed produced by the Washington State Crop Improvement Association. Cultural practices were the same as described above except that colonized oat kernels were spread on 10 October 1995 at the rate of $50 \mathrm{~kg} / \mathrm{h}$. This plot was established to increase the inoculum density of $C$. gramineum in the field for a subsequent experiment; it was used for this experiment due to the extensive development of Cephalosporium stripe.

The Fort Hall plot was located in a commercial production field that was planted to winter wheat in alternating years with potato (2 years of wheat, 1 year of potatoes) on Tindahay Loamy Coarse Sand (sandy, mixed, mesic Xeric Torriorthents). The field was irrigated with an overhead center-pivot system. Three winter wheat cultivars, Eltan, Madsen, and Stephens, and breeding line 87-00314A (University of Idaho Winter Wheat Breeding Program) were seeded on 18 September and 7 Octo- ber 1997 in four-row plots $(7.6 \times 1.5 \mathrm{~m}$ with $0.3 \mathrm{~m}$ between rows) with a grain drill at approximately $90 \mathrm{~kg} / \mathrm{ha}$. Four replicates were planted for each genotype in a randomized complete block design. Other cultural practices such as soil fertility and weed control were consistent with local commercial practices. Supplemental inoculum was not added to this plot.

Disease evaluation. The incidence and severity of Cephalosporium stripe at PIP were determined as described previously (20); stems from a 0.5 -m-long section of a row were removed after anthesis (1 to 2 July 1996), and individual stems were scored visually for the presence of symptoms using a rating scale that ranged from 0 to 5 where $0=$ no visible symptoms in the upper four leaves, $1=$ stripes in the third leaf below the flag leaf, $2=$ stripes in the second leaf below the flag leaf, $3=$ stripes in the first leaf below the flag leaf, $4=$ stripes in the flag leaf, and $5=$ symptoms in the head (19). Disease incidence was calculated as the percentage of stems with symptoms, and disease severity as the average rating of symptomatic stems. Symptoms of Cephalosporium stripe were observed in the FH plot, but no estimates of disease incidence or severity were made.

Plants from PCFS were sampled at maturity by cutting stems near the base and sorting them based on presence or absence of visual symptoms. Stems were grouped into those with severe disease (visual score of 4 or 5) and those with no apparent symptoms (visual score of 0 ). Seed was

Table 1. Incidence and severity of Cephalosporium stripe and percent seed from which Cephalosporium gramineum was isolated for 12 winter wheat cultivars grown at the WSU Plant Pathology Farm, Pullman, WA, 1995 to 1996

\begin{tabular}{lccc}
\hline Variety & Disease incidence $^{\mathbf{a}}$ & Disease severity & $\begin{array}{c}\text { \% C. } \text { gramineum- }^{\text {infected seeds }} \\
\text { ind }^{\mathbf{2}}\end{array}$ \\
\hline Lewjain & 45.6 & 3.7 & 0 \\
Daws & 45.6 & 4.1 & 0.10 \\
Nugaines & 50.2 & 3.7 & 0.51 \\
Lambert & 50.4 & 4.0 & 0.20 \\
Eltan & 50.8 & 3.5 & 0.10 \\
Cashup & 53.6 & 4.0 & 0.20 \\
Madsen & 59.1 & 4.0 & 0.20 \\
Kmor & 59.4 & 3.9 & 0.39 \\
Hill 81 & 60.9 & 4.0 & 0.50 \\
Rod & 67.3 & 4.0 & 0.88 \\
Gene & 77.9 & 4.2 & 0.40 \\
Stephens & 88.7 & 4.3 & 0.39 \\
LSD, 5\% & $13.5^{\mathrm{c}}$ & $0.2^{\mathrm{c}}$ & $\mathrm{ns}^{\mathrm{c}}$ \\
\hline
\end{tabular}

${ }^{a}$ Disease incidence and severity were determined by removing 0.5-m sections of row 1 July 1996 and rating each stem for severity of symptoms on a 0 to 5 scale where $0=$ no symptoms in the uppermost four leaves or head, $1=$ symptoms in the fourth leaf below the head, $2=$ symptoms in the third leaf below the head, 3 = symptoms in the leaf subtending the flag leaf, $4=$ symptoms in the flag leaf, and $5=$ symptoms in the head. Disease incidence was calculated as the percentage of stems with symptoms in the uppermost four leaves or head, and disease severity was the average rating of symptomatic stems.

${ }^{\mathrm{b}}$ Seed of each cultivar were bulked after harvest, and two lots of 500 seed each $(1,000$ total per cultivar) were surface-disinfected, placed on a medium semi-selective for $C$. gramineum, and then incubated for 2 to 4 weeks at $15^{\circ} \mathrm{C}$ before determining the percentage of infected seeds.

${ }^{\mathrm{c}}$ Figures for disease incidence and severity are the mean of six replicates. Data were subjected to ANOVA and Fisher's least significant difference $(P=0.05)$ used to differentiate means. Due to the nonparametric nature of seed infection data, means were compared using the chi-square test for independence. ns $=$ not significantly different at $P=0.05$. threshed from each group separately using a bundle thresher.

Seed was harvested at maturity from individual plots using a small plot combine, bulked by cultivar and planting date, and stored dry at room temperature until isolation of the pathogen. Isolation of the pathogen began within 3, 5, and 9 months of harvest for PIP, PCFS, and FH, respectively.

Isolation of $C$. gramineum from seed. Seed from each cultivar were surfacedisinfected by placing seeds in a beaker with $95 \%$ ethanol for 2 min while stirring with a magnetic stir bar. The ethanol was decanted and seeds were then disinfested in a solution with $1 \%$ available sodium hypochlorite for $2 \mathrm{~min}$ with stirring. Seeds were then rinsed three times for $30 \mathrm{~s}$ each with sterile deionized water. Seeds were placed on sterile moist filter paper in 10$\mathrm{cm}$-diameter plastic petri dishes (approximately 50 per dish) and incubated for $24 \mathrm{~h}$ at room temperature (RT; approximately $20^{\circ} \mathrm{C}$ ), frozen at $-20^{\circ} \mathrm{C}$ for $20 \mathrm{~h}$ (1) to kill the seed and prevent germination, placed on $C$. gramineum semi-selective medium (CGSM) (18), and then incubated at $15^{\circ} \mathrm{C}$ in the dark. Beginning 2 weeks after plating and at 1-week intervals thereafter up to 1 month, seed were examined with a stereo microscope for fungal colonies resembling C. gramineum; conidia were removed from putative colonies and examined with a compound microscope to confirm their identity.

For seed from PIP and FH, two lots of approximately 500 seed for each cultivar and seeding date (FH only) were tested (1,000 seed/cultivar/seeding date). For seed from PCFS, four lots of approximately 500 seed each were tested from severely diseased and visually disease-free plants (2,000 seed each).

Transmission of $C$. gramineum from seed. Only seed from PCFS and FH were used in transmission studies. Approximately 250 seed each from infected and symptomless Stephens (PCFS), and 500 seed from each cultivar or breeding line $(\mathrm{FH})$, were planted in separate experiments to determine whether $C$. gramineum was seed transmitted. Each experiment was conducted twice. Seed were placed on moist filter paper, imbibed for 4 days at $4^{\circ} \mathrm{C}$, and then planted, 4 seeds per pot, into a soilless potting mix (Sun. Gro. Hort. Inc., Puyallup, WA) in 15-cm-diameter plastic pots. Plants were grown at $17^{\circ} \mathrm{C}$ for 4 weeks in a growth chamber, vernalized at $5^{\circ} \mathrm{C}$ for 6 weeks, postvernalized at $17^{\circ} \mathrm{C}$ for 3 weeks, and then moved to a greenhouse until anthesis (19). At anthesis, plants were rated visually for symptoms of Cephalosporium stripe using the scale described above.

Isolation of the pathogen was done from all symptomatic leaves by placing surface-disinfected leaves onto CGSM. The soilless potting mix was tested for 
the presence of $C$. gramineum by soil dilution-plating onto CGSM prior to planting and from control pots (potting mix only) during postvernalization to confirm that the pathogen was not present in the mix (18).

Statistical analysis. Due to its nonparametric nature, data for seed infection and transmission were analyzed using the chi-square test for independence (10). Linear correlation between disease incidence and disease severity with percent seed infection were calculated for data from the Plant Pathology Farm. Data for disease incidence and severity were subjected to ANOVA and means separated using Fisher's least significant difference (SAS Institute Inc., Cary, NC).

\section{RESULTS}

Plant Pathology Farm, 1996. $C$. gramineum was isolated from 0 to $0.88 \%$ of seed and from all cultivars examined except Lewjain (Table 1). Differences among cultivars for seed infection were not significantly different according to the chi-square test for independence. Disease incidence ranged from 45.6 to $88.7 \%$ affected stems, and severity ranged from 3.5 to 4.3 (Table 1). The correlations between disease incidence $(r=0.504)$ and disease severity $(r=0.159)$ with seed infection were not significant $(P=0.05)$.

Palouse Conservation Field Station, 1996. C. gramineum was isolated from 0.55 and $0.35 \%$ of seed from plants with severe symptoms and no visible symptoms of Cephalosporium stripe, respectively (Table 2); this difference was not statistically significant according to the chisquare test for independence.

When seed from these same lots were grown under controlled environment conditions, 0.18 and $0.55 \%$ of the plants grown from seed of plants with no visible symptoms or severe symptoms of Cephalosporium stripe, respectively, developed symptoms of Cephalosporium stripe. There was no significant difference in the transmission rate between these samples based on chi-square test for independence. Isolation of the pathogen from symptomatic leaves confirmed the presence of the pathogen in all symptomatic plants and, as expected, C. gramineum was not detected in the soilless potting mix used for these tests by soil dilution-plating.

Fort Hall, ID, 1998. C. gramineum was isolated from 0.05 to $0.25 \%$ of seed of two cultivars and one winter wheat breeding line (Table 3); C. gramineum was not isolated from Eltan winter wheat. When the seed from these lots was grown under controlled environment, symptoms of Cephalosporium stripe developed on 0.08 and $0.17 \%$ of Stephens and breeding line 87 00314A plants, respectively (Table 3). Isolation of $C$. gramineum from leaves confirmed the presence of the pathogen in all symptomatic plants. C. gramineum was not detected in the soilless potting mix by soil dilution-plating.

\section{DISCUSSION}

Cephalosporium stripe developed in up to $0.55 \%$ of plants grown from seed lots with seed infected by $C$. gramineum, thus demonstrating that this pathogen can be seed transmitted. Although previous studies $(5,17)$ have reported that Cephalosporium stripe developed on plants grown in noninfested field soil with seed harvested from infected plants, neither study reported how field soil was determined to be free of C. gramineum. Furthermore, in one of those studies (17), C. gramineum was not isolated from the seed lot used to establish the field plot, and thus the possibility that soilborne inoculum and not infected seed was responsible for the observed disease cannot be eliminated. In this study, seed from infected plants was grown under controlled environment conditions in a soilless potting mix in which $C$. gramineum was confirmed not to be present, thus ensuring that infected seed was the only possible source of inoculum.

Bruehl (5) did not report a seed transmission rate in his studies, but observed that a "few" infected plants developed in his plots and concluded that seed transmission is too low to produce an epidemic. Nisikado et al. (17) reported transmission rates ranging up to $0.18 \%$ for seed from infected plants sown into "healthy" soil and also concluded that seed was not an important source of inoculum. We isolated C. gramineum from 12 different winter wheat cultivars and breeding lines, which differ in susceptibility to the pathogen $(14,15)$, grown in three different locations in two different growing seasons at rates (Tables 1 to 3 ) comparable to or greater than those reported by Nisikado (17). We also documented transmission of $C$. gramineum from seed to plants of two cultivars grown at different locations and from seed produced on plants with no visible symptoms at a low, but not significantly different, rate than plants with severe disease (Table 2). Although the rate of seed transmission for C. gramineum is too low to start an epidemic in the first year of introduction, it is great enough to allow the pathogen to become established in fields where it is not present and become a significant problem in subsequent crops. For example, Bruehl et al. (6) found that wheat

Table 2. Percent seed from which Cephalosporium gramineum was isolated and the percent plants with symptoms of Cephalosporium stripe for cv. Stephens winter wheat collected from plants grown at the Palouse Conservation Field Station, Pullman, WA, 1995 to 1996

\begin{tabular}{|c|c|c|}
\hline Seed lot ${ }^{a}$ & $\begin{array}{l}\% \text { C. gramineum- } \\
\text { infected seed }^{\mathrm{b}}\end{array}$ & $\begin{array}{l}\% \text { C. gramineum- } \\
\text { infected plants }\end{array}$ \\
\hline Severely diseased & 0.55 & 0.55 \\
\hline \multirow[t]{2}{*}{ Symptomless } & 0.35 & 0.18 \\
\hline & $n s^{\mathrm{d}}$ & ns \\
\hline
\end{tabular}

a Seed designated as severely diseased were collected from plants with severe, visual symptoms of Cephalosporium stripe and the symptom-less seed are from plants with no apparent visual symptoms.

b Seed were surface disinfected, placed on a medium semi-selective for $C$. gramineum, and then incubated for 2 to 4 weeks at $15^{\circ} \mathrm{C}$ before determining the percentage of infected seeds. Four lots of 500 seed each were tested.

${ }^{c}$ Seed were planted into a soilless potting mix and grown at $17^{\circ} \mathrm{C}$ for 4 weeks, vernalized at $5^{\circ} \mathrm{C}$ for 6 weeks, post-vernalized at $17^{\circ} \mathrm{C}$ for 3 weeks, and then moved to a greenhouse until anthesis when plants were evaluated visually for the presence of symptoms. Two lots of 250 seed each were tested in two separate experiments.

${ }^{\mathrm{d}}$ Due to the nonparametric nature of the data, means were compared using the chi-square test for independence. $\mathrm{ns}=$ not significantly different at $P=0.05$.

Table 3. Percent seed from which Cephalosporium gramineum was isolated and the percent plants with symptoms of Cephalosporium stripe for three winter wheat cultivars and one breeding line grown in Fort Hall, ID, 1997 to 1998

\begin{tabular}{lcc}
\hline Cultivar or breeding line & $\begin{array}{c}\text { \% C. gramineum- } \\
\text { infected seed }\end{array}$ & $\begin{array}{c}\text { \% C. } \text { gramineum- }^{\mathbf{a}} \\
\text { infected plants }^{\mathbf{b}}\end{array}$ \\
\hline Eltan & 0 & 0 \\
Madsen & 0.05 & 0 \\
Stephens & 0.20 & 0.08 \\
87-00314A & 0.25 & 0.17 \\
& $\mathrm{~ns}^{\mathrm{c}}$ & $\mathrm{ns}$ \\
\hline
\end{tabular}

a Seed were surface-disinfected, placed on a medium semi-selective for C. gramineum, and then incubated for 2 to 4 weeks at $15^{\circ} \mathrm{C}$ before determining the percentage of infected seeds. Figures represent the mean of two lots of 500 seed each and two seeding dates for each cultivar or breeding line for a total of 2,000 seed

b Seed were planted into a soilless potting mix and grown at $17^{\circ} \mathrm{C}$ for 4 weeks, vernalized at $5^{\circ} \mathrm{C}$ for 6 weeks, postvernalized at $17^{\circ} \mathrm{C}$ for 3 weeks, and then moved to a greenhouse until anthesis, when plants were evaluated visually for the presence of symptoms. Two lots of 250 seed each were tested in two separate experiments.

${ }^{c}$ Due to the nonparametric nature of the data, means were compared using the chi-square test for independence. $\mathrm{ns}=$ not significantly different at $P=0.05$. 
plants infected with Cephalosporium produce an average of $35.3 \mathrm{~kg} / \mathrm{ha}$ of infested straw for every $1 \%$ infected stems; assuming the highest rates of seed transmission observed in this study, $0.55 \%$, would result in up to $19.4 \mathrm{~kg}$ of infested straw per ha in the first crop following introduction. Bruehl et al. (6) found that the inoculum load necessary to cause a significant increase in disease in a susceptible cultivar such as Stephens was as little as $13 \mathrm{~kg} / \mathrm{ha}$ of host debris, and therefore, planting seed infected by $C$. gramineum at rates observed herein could produce enough inoculum to initiate an epidemic in a subsequent crop, especially when a susceptible cultivar is planted.

Lewjain, the only cultivar from which the pathogen was not isolated, is reported to be tolerant to Cephalosporium stripe (6) and had the lowest disease incidence, along with Daws, of the cultivars tested in Pullman 1996 (Table 1). Although the correlation between disease incidence and disease severity with seed infection was not significant, there was a trend toward increasing percent infected seed with increasing disease incidence (Table 1). Cultivars did not differ significantly for seed infection, and thus it appears that all cultivars in this study in which disease developed may have the potential to transmit $C$. gramineum through seed.

The results of this study confirmed what other researchers $(1,17)$ have reported, namely, that $C$. gramineum can be isolated from winter wheat seed produced under field conditions. We further demonstrated that the pathogen is seed transmitted, albeit at very low rates. A new, highly effective source of resistance to $C$. gramineum has been identified in a wild relative of wheat and transferred to adapted winter wheat breeding lines (T. D. Murray and S. S. Jones, unpublished) that are being evaluated in local breeding programs. Further work is needed to determine whether seed infection and transmission of $C$. gramineum is affected by this source of resistance. Additional work is also needed to determine how long the pathogen survives in seed and whether fungicide seed treatments have an effect on transmission. Improved methods of detecting $C$. gramineum in seed are needed to facilitate these studies since the cultural method used in this study is labor-intensive and requires 2 to 4 weeks to determine whether seed is infected by $C$. gramineum.

\section{ACKNOWLEDGMENTS}

Plant Pathology New Series 0401. Financial support was provided by the College of Agricultural, Human, and Natural Resource Sciences Agricultural Research Center, Project 0670, Washington State University, Pullman 991646430, the Washington State Wheat Commission, and the O. A. Vogel Wheat Research Fund. The assistance of Larry Robertson, Cooperative Extension, University of Idaho, Aberdeen, in providing seed from the Fort Hall plots and the technical assistance of C. A. Blank and L. Pritchett are gratefully acknowledged.

\section{LITERATURE CITED}

1. Arneson, E., and Stiers, D. L. 1977. Cephalosporium gramineum: A seedborne pathogen. Plant Dis. Rep. 61:619-621.

2. Bailey, J. E., Lockwood, J. L., and Wiese, M. V. 1982. Infection of wheat by Cephalosporium gramineum as influenced by freezing of roots. Phytopathology 72:1324-1328.

3. Blank, C. A., and Murray, T. D. 1998. Seed transmission of Cephalosporium gramineum in winter wheat. (Abstr.) Phytopathology 88:S106.

4. Bockus, W. W., O'Conner, J. P., and Raymond, P. J. 1983. Effect of residue management method on incidence of Cephalosporium stripe under continuous winter wheat production. Plant Dis. 67:1323-1324.

5. Bruehl, G. W. 1957. Cephalosporium stripe disease of wheat. Phytopathology 47:641-649.

6. Bruehl, G. W., Murray, T. D., and Allan, R. E. 1986. Resistance of winter wheats to Cephalosporium stripe in the field. Plant Dis. 70:314316.

7. Bruehl, G. W., and Nelson, W. L. 1964. Technique for mass inoculations of winter wheat in the field with Cercosporella herpotrichoides. Plant Dis. Rep. 48:287-289.
8. Douhan, G. W., and Murray, T. D. 2001. Infection of winter wheat by a $\beta$-glucuronidasetransformed isolate of Cephalosporium gramineum. Phytopathology 91:232-239.

9. Johnson, R. H., and Mathre, D. E. 1972. Effect of infection by Cephalosporium gramineum on winter wheat. Crop Sci. 12:817-819.

10. Little, T. M., and Hills, F. J. 1978. Agricultural Experimentation: Design and Analysis. John Wiley \& Sons, Inc., New York.

11. Martin, J. M., Johnston, R. H., and Mathre, D. E. 1989. Factors affecting the severity of Cephalosporium stripe of winter wheat. Can. J. Plant Pathol. 11:361-367.

12. Mathre, D. E., and Johnston, R. H. 1975 Cephalosporium stripe of winter wheat: Infection processes and host response. Phytopathology 65:1244-1249.

13. Mathre, D. E., and Johnston, R. H. 1977. Physical and chemical factors affecting sporulation of Hymenula cerealis. Trans. Br. Mycol. Soc. 69:213-215.

14. Murray, T. D., and Pritchett, L. C. 1998. Reaction of winter wheat cultivars and breeding lines to Cephalosporium stripe, 1997. Biol. Cult. Tests Control Plant Dis. 13:123.

15. Murray, T. D., Pritchett, L., Jones, S. S., and Lyon, S. 2001. Reaction of winter wheat cultivars and breeding lines to Cephalosporium stripe, 2000. Biol. Cult. Tests Control Plant Dis. 2001:S21.

16. Murray, T. D., Walter, C. C., and Anderegg, J. C. 1992. Control of Cephalosporium stripe of winter wheat by liming. Plant Dis. 76:282-286.

17. Nisikado, Y., Matsumoto, H., and Yamauti, K. 1934. Studies on a new Cephalosporium, which causes the stripe disease of wheat Berichte d. Ohara Inst. f. Landow. Forsch. 6:275-306

18. Specht, L. P., and Murray, T. D. 1989. Sporulation and survival of conidia of Cephalosporium gramineum as influenced by soil $\mathrm{pH}$, soil matric potential, and soil fumigation. Phytopathology 79:787-793.

19. Specht, L. P., and Murray, T. D. 1990. Effects of root-wounding and inoculum density on Cephalosporium stripe in winter wheat. Phytopathology 80:1108-1114.

20. Stiles, C. M., and Murray, T. D. 1996. Infection of field-grown winter wheat by Cephalosporium gramineum and the effect of soil pH. Phytopathology 86:177-183.

21. Wiese, M. V. 1972. Colonization of wheat seedlings by Cephalosporium gramineum in relation to symptom development. Phytopathology 62:1013-1018. 